\title{
Anti-asthmatic effect of laurotetanine extracted from Litsea cubeba (Lour.) Pers. root on ovalbumin-induced allergic asthma rats, and elucidation of its mechanism of action
}

\author{
Xinxin Xing, Hai Wang* \\ First Affiliated Hospital of Heilongjiang University of Chinese Medicine, Harbin 150040, PR China \\ ${ }^{*}$ For correspondence: Email: wanghhljutcm@126.com; Tel: +86-451821114016911
}

Sent for review: 21 October 2018

Revised accepted: 21 May 2019

\begin{abstract}
Purpose: To investigate the anti-asthmatic effect of laurotetanine on allergic asthma rat model. Methods: Laurotetanine was extracted from the roots of Litsea cubeba (Lour.) Pers. Asthma was induced in rats by ovalbumin injection. Laurotetanine $(20,40$, or $60 \mathrm{mg} / \mathrm{kg})$ was administered orally to the rats for 21 days. Inflammatory cells and cytokines released by T-cell subsets Th1 and Th2 in the bronchoalveolar lavage fluid were determined. Serum immunoglobulin $E(I g E)$ and histamine, in addition to expression of mucin 5AC (MUC-5AC), nuclear factor-kappa B (NF-KB), and an inhibitor of NF-KB (IKB) in lung tissues were also evaluated.

Results: Laurotetanine treatment $(20,40,60 \mathrm{mg} / \mathrm{kg})$ significantly reduced inflammatory cells, including eosinophils, neutrophils, lymphocytes, and macrophages in treated rats compared with control animals $(p<0.01)$. Inflammatory cytokines, viz, interleukin (IL) -4, IL-6, IL-13 were also significantly $(p<0.01)$ decreased by laurotetanine treatment $(20,40,60 \mathrm{mg} / \mathrm{kg}$ ), whereas interferon gamma (IFN- $\gamma$ ) was increased $(p<0.01)$. Serum IgE and histamine were significantly reduced $(p<0.01)$ by laurotetanine $(20,40,60 \mathrm{mg} / \mathrm{kg})$. Furthermore, MUC5AC expression in lung tissues was significantly $(p<0.01)$ downregulated by laurotetanine $(20,40$, and $60 \mathrm{mg} / \mathrm{kg}$, but NF-KB and $\mathrm{I} K B$ were significantly $(p<0.01)$ upregulated by laurotetanine $(20,40$, and $60 \mathrm{mg} / \mathrm{kg})$.

Conclusion: Laurotetanine exerts an anti-asthmatic effect in rats by inhibition of $\operatorname{lgE}$, histamine, and inflammatory reactions via down-regulating MUC5AC and NF-KB signaling pathways. This finding justifies the need for further development of laurotetanine as a potential anti-asthmatic drug.
\end{abstract}

Keywords: Allergic asthma, treatment of asthma, laurotetanine, inflammation, IgE inhibition

This is an Open Access article that uses a fund-ing model which does not charge readers or their institutions for access and distributed under the terms of the Creative Commons Attribution License (http://creativecommons.org/licenses/by/4.0) and the Budapest Open Access Initiative (http://www.budapestopenaccessinitiative.org/read), which permit unrestricted use, distribution, and reproduction in any medium, provided the original work is properly credited.

Tropical Journal of Pharmaceutical Research is indexed by Science Citation Index (SciSearch), Scopus, International Pharmaceutical Abstract, Chemical Abstracts, Embase, Index Copernicus, EBSCO, African Index Medicus, JournalSeek, Journal Citation Reports/Science Edition, Directory of Open Access Journals (DOAJ), African Journal Online, Bioline International, Open-J-Gate and Pharmacy Abstracts

\section{INTRODUCTION}

Allergic asthma is a common, intractable, allergyrelated airway disease that is seriously affecting the quality of life of millions people of all ages around the world [1,2]. Allergic asthma is characterized by severe airway inflammatory reactions, airflow obstruction, airway hyperreactivity, and excessive sputum in airways $[3,4]$. Recent epidemiological research indicates that allergic asthma morbidity and mortality have been increasing dramatically for decades and that there are currently more than 300 million patients with allergic asthma worldwide [4]. 
However, currently available drugs, such as inhalation corticosteroids and $\beta$-2-agonists, can only temporarily control or relieve allergic asthma symptoms [5]. Therefore, there is an urgent need to develop more effective drugs to treat allergic asthma symptoms.

Recently, more attention has been focused on herbal medicines and their curative effects on immune-related diseases, such as allergic asthma, rheumatoid arthritis (RA), and cancers $[6,7]$. The root of Litsea cubeba (Lour.) Pers. ( $L$. cubeba) has been used as a folk herbal medicine to treat asthma, RA, and other inflammatory disorders for many years in China [8,9]. Nowadays, a great many monomers have been isolated from the root of $L$. cubeba, some of which possess anti-inflammatory and antibacterial properties [9,10]. Laurotetanine (Figure 1 ) is one of the main constituents of the root of $L$. cubeba [11,12]. However, to date, there are no systematic experimental investigations regarding the anti-asthmatic effect and potential molecular mechanisms of action of laurotetanine or other active substances of $L$. cubeba.

Consequently, the present study was designed to explore the anti-asthmatic properties and mechanism of action of laurotetanine in ovalbumin (OVA)-induced allergic asthmatic rats to advance the development of this compound as a novel anti-asthmatic drug.<smiles>COC1=C(O)C2=C3c4cc(OC)c(O)cc4CC3NCCC2=C1</smiles>

Figure 1: Structure of laurotetanine from the roots of L. cubeba

\section{EXPERIMENTAL}

\section{Chemicals and materials}

The roots of $L$. cubeba were acquired from the Tongren drug store (Harbin, China). Aluminum hydroxide and OVA were obtained from Sigma Co. Ltd. (Shanghai, China). Montelukast sodium tablets were purchased from Hang MSD Pharmaceuticals Company (Hangzhou, China). All the enzyme-linked immunosorbent assay (ELISA) kits for interleukin (IL)-4,

IL-6, IL-13, interferon (IFN)- $\mathrm{y}$, histamine, and immunoglobulin $\mathrm{E}(\mathrm{lg} \mathrm{E})$ in bronchoalveolar lavage fluid (BALF) were purchased from eBioscience Biotech. Co. (Shanghai, China). Radio-immunoprecipitation assay (RIPA) lysis buffer, bicinchoninic acid (BCA) protein assay kit, horseradish peroxidase (HPR)-conjugated secondary antibodies, phosphate buffer saline (PBS), and enhanced chemiluminescence (ECL) kits were acquired from Beyotime Biotech. Co. (Hangzhou, China). Polyvinylidene difluoride (PVDF) membrane was acquired from Millipore Biotech. (MA, USA). The first antibodies of mucin 5AC (MUC5AC), nuclear factor-kappa B (NF-kB) p65, inhibitor of NF-kB (IKB), and glyceraldehyde 3-phosphate dehydrogenase (GAPDH) were acquired from Abcam Co. (Cambridge, UK).

\section{Extraction of laurotetanine from $L$. cubeba root}

Extraction of laurotetanine was carried out according to a previously reported procedure $[11,13]$. Dried $L$. cubeba roots were powdered and subsequently extracted by reflux three times ( $2 \mathrm{~h}$ each time) with $75 \%$ ethanol. The ethanol extracts were subsequently combined and evaporated to dryness under vacuum. The resultant residue was suspended in water and partitioned with petroleum ether (PE), chloroform $\left(\mathrm{CHCl}_{3}\right)$, ethyl acetate (EtOAc), and n-butyl alcohol (n-BuOH). Next, the EtOAc fraction was subjected to successive silica gel (100-200 mesh) column chromatography eluting with PE:EtOAc eluents at ratios of 20:1, 15:1, 10:1, $5: 1,2: 1$, and $1: 1$, to afford six sub-fractions (Frs.Et1-Et6).

Fr.Et4 was further separated with repeated silica gel (200-300 mesh) column chromatography elutions using $\mathrm{PE}: \mathrm{EtOAc}$, at a ratio of $7: 1$, to afford the pure target compound laurotetanine. The purity of laurotetanine was determined by HPLC assay, and the chemical structure of laurotetanine was confirmed by ${ }^{1} \mathrm{H}$ NMR and ${ }^{13} \mathrm{C}$ NMR analyses.

\section{Animal studies}

A total of 60 Sprague Dawley (SD) rats (180-220 g) were purchased from SLARC Co. (Shanghai, China). All the animals received humane care following the "Guidelines for Ethical Conduct in the Care and Use of Non-human Animals in Research" [14]. The protocols were approved by the Animal Care and Use Committee of Heilongjiang University of Chinese Medicine (Harbin, China) (Certificate no. 20180124a-002). The rats were randomly divided into six groups ( $\mathrm{n}$ = 10); namely, normal, asthma model control, positive drug control (Montelukast was used as the positive control drug, $30 \mathrm{mg} / \mathrm{kg} /$ day), and 
three laurotetanine groups $(20,40$, and 60 $\mathrm{mg} / \mathrm{kg} /$ day).

The protocol was carried out following published methods with some modifications $[15,16]$. To induce asthma in rats, animals were treated with a mixture of $50 \mathrm{mg}$ of OVA and $2 \mathrm{mg}$ of aluminum hydroxide by intraperitoneal injection (ip) on the $1^{\text {st }}$ and $14^{\text {th }}$ days of the experiment. On the $21^{\text {st }}$ and $28^{\text {th }}$ days, rats were challenged with a 5\% OVA saline solution administered by inhalation for 30 min using an OMRON ultrasonic nebulizer (Tokyo, Japan).

All drugs were administered orally on the $28^{\text {th }}$ and $56^{\text {th }}$ days. Then, blood samples were collected via the abdominal aorta. The rats were subsequently anesthetized with pentobarbital sodium (40 mg/kg, ip) and euthanized. Next, cold PBS was infused into the bronchus and the BALFs were collected and stored at $-70^{\circ} \mathrm{C}$ for future biochemical assays. Furthermore, inflammatory cell counts, including eosinophils, neutrophils, lymphocytes, and macrophages in BALFs, were carried out according to the reported method [17].

\section{Determination of serum IgE and histamine}

Blood samples were centrifuged (4,000 rpm, 10 $\min )$ to separate the serum. Then, the $\lg E$ and histamine in serum were measured using ELISA assay kits according to the manufacturer's instructions.

\section{Determination of IL-4, IL-6, IL-13, and IFN-Y}

The cytokines in BALFs, including IL-4, IL-6, IL13, and IFN- $\gamma$, were measured using ELISA assay kits according to the manufacturer's instructions.

\section{Western blot assay}

Lung tissues were collected and homogenized in RIPA lysis buffer. Tissue homogenates were centrifuged at $4^{\circ} \mathrm{C}$ and $10,000 \mathrm{rpm}$ for $30 \mathrm{~min}$, and the supernatants were collected and treated as the total proteins samples. The protein concentrations of the total proteins samples were determined using a BCA protein assay kit. Then, $35 \mu \mathrm{g}$ of proteins were separated using sodium dodecylsulfate-polyacrylamide gel electrophoresis (SDS-PAGE) and then transferred and blotted to a PVDF membrane.

The PVDF membrane was incubated with primary antibodies of MUC5AC, NF-kB p65, and IKB, sequentially, and subsequently incubated with HPR-conjugated secondary antibodies.
Next, the target protein bands were visualized by chemiluminescence using an ECL kit. GAPDH was used as the internal reference to normalize the loading samples.

\section{Statistical analysis}

Student's t-test and one-way analysis of variance (ANOVA) were performed using SPSS 18.0 (IBM, USA). All the data are represented as mean \pm standard deviation, and a $p$ value of less than 0.05 was considered significant.

\section{RESULTS}

\section{Structural characteristics of laurotetanine extracted from Litsea cubeba}

Our results indicate that the purity of laurotetanine was > $98 \%$ based on HPLC analysis using area normalization method (Figure 2). In addition, the spectra of ${ }^{1} \mathrm{H}-\mathrm{NMR}$ and ${ }^{13} \mathrm{C}$ NMR of laurotetanine shown in Table 1 are in good agreement with the reported literature data for laurotetanine $[8,10]$.

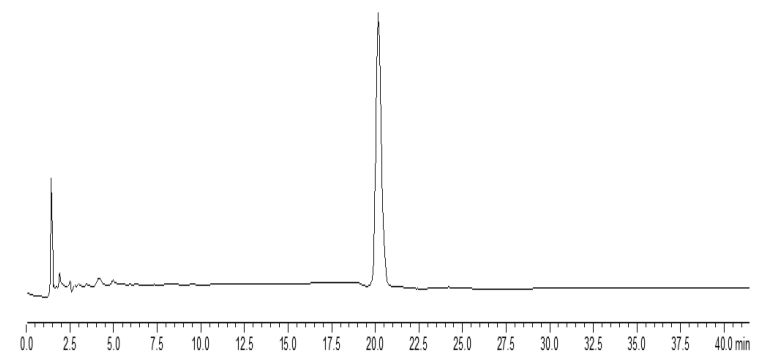

Figure 2: Purity determination of laurotetanine by HPLC assay. HPLC assay was performed using an Agilent 1100 HPLC system using a $\mathrm{C}_{18}$ chromatographic column $(250 \mathrm{~mm} \times 4.6 \mathrm{~mm}, 5 \mu \mathrm{m})$ eluting with $\mathrm{MeOH}-0.2 \%$ phosphoric acid (65: 35) at $215 \mathrm{~nm}$. The flow rate was $1.0 \mathrm{~mL} / \mathrm{min}$, and the laurotetanine was dissolved in $\mathrm{MeOH}$ and sample injection volume was $10 \mu \mathrm{L}$, and the column temperature was $30 \stackrel{\circ}{\mathrm{C}}$

\section{Laurotetanine suppressed inflammatory cells in BALFs}

The effects of laurotetanine on inflammatory cells in BALFs (including eosinophils, neutrophils, lymphocytes, and macrophages) are shown in Figure 3. After OVA challenge, all four inflammatory cells of asthma control rats increased sharply $(p<0.01)$ compared to normal rats. However, Montelukast (30 mg/kg) significantly reversed the abnormal, increased inflammatory cells in BALFs $(p<0.01$, vs. control). Similar to Montelukast, laurotetanine $(20,40$, and $60 \mathrm{mg} / \mathrm{kg})$ also significantly 
Table 1: ${ }^{1} \mathrm{H}$ NMR $(600 \mathrm{MHz})$ and ${ }^{13} \mathrm{C}$ NMR $(150 \mathrm{MHz})$ data for laurotetanine $\left(\mathrm{CD}_{3} \mathrm{OD}, \mathrm{\delta}, \mathrm{ppm}\right)$

\begin{tabular}{|c|c|c|c|c|c|}
\hline No. & $\delta_{H}(J)$ & $\delta_{c}(J)$ & No. & $\delta_{H}(J)$ & $\delta_{c}(J)$ \\
\hline 1 & & 142.95 & 7 & $2.74,3.17(2 \mathrm{H}, \mathrm{m})$ & \\
\hline $1 \mathrm{a}$ & & 122.17 & $7 a$ & & 127.03 \\
\hline $1 b$ & & 125.03 & 8 & $6.79(1 \mathrm{H}, \mathrm{s})$ & 114.09 \\
\hline 2 & & 159.06 & 9 & & 144.93 \\
\hline 3 & $6.76(1 \mathrm{H}, \mathrm{s})$ & 111.02 & 10 & & 143.01 \\
\hline $3 a$ & & 126.04 & 11 & $7.69(1 \mathrm{H}, \mathrm{s})$ & 109.87 \\
\hline 4 & $2.65,2.78(2 \mathrm{H}, \mathrm{m})$ & & $11 \mathrm{a}$ & & 119.67 \\
\hline 5 & 3.27,3.03 (2H, m) & & $1-\mathrm{OCH}_{3}$ & $3.51(3 \mathrm{H}, \mathrm{s})$ & 58.13 \\
\hline \multirow[t]{2}{*}{$6 a$} & $4.15(1 \mathrm{H}, \mathrm{J}=12.1 \mathrm{~Hz})$ & & $2-\mathrm{OCH}_{3}$ & $3.94(3 \mathrm{H}, \mathrm{s})$ & 54.96 \\
\hline & & & $10-\mathrm{OCH}_{3}$ & $3.76(3 \mathrm{H}, \mathrm{s})$ & 54.87 \\
\hline
\end{tabular}

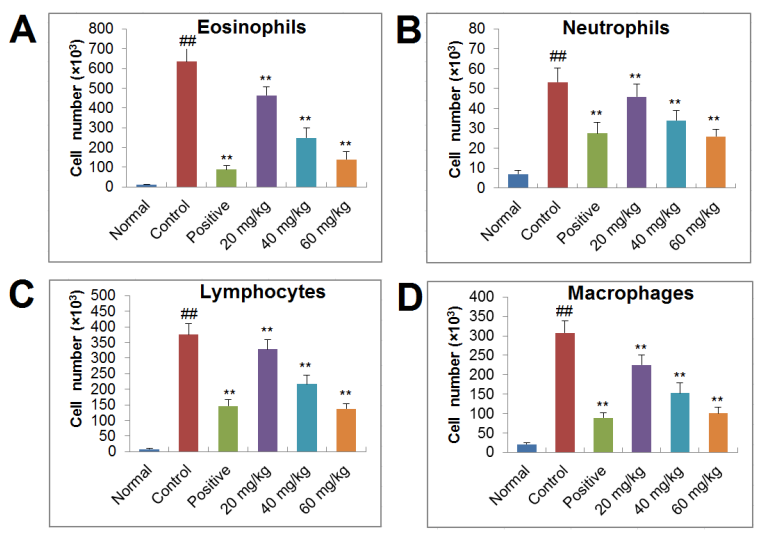

Figure 3: Effect of Laurotetanine on eosinophils (A), neutrophils (B), lymphocytes (C) and macrophages (D) in BALFs. Data are represented as mean $\pm \mathrm{SD}(\mathrm{n}=$ $10) ;{ }^{\# \#} p<0.01$ vs. Normal; ${ }^{* *} p<0.01$, vs. Control

decreased the four inflammatory cells in BALFs of asthmatic rats $(p<0.01)$.

\section{Laurotetanine suppressed the levels of $\lg E$ and histamine in serum}

The levels of $\lg E$ and histamine in serum of asthmatic rats are summarized (Figure 4). After OVA challenge, the levels of serum $\lg \mathrm{E}$ and histamine in asthma control rats significantly increased compared with normal rats $(p<0.01)$. However, the positive control drug Montelukast $(30 \mathrm{mg} / \mathrm{kg}$ ) significantly reduced the serum $\mathrm{lgE}$ and histamine levels in asthmatic rats $(p<0.01$, vs. control rats). Interestingly, similar to Montelukast treatment, the laurotetanine treatments $(20,40$, and $60 \mathrm{mg} / \mathrm{kg})$ also significantly decreased the levels of $\lg \mathrm{E}$ and histamine in the serum of asthmatic rats $(p<$ 0.01 , vs. control rats).

\section{Laurotetanine regulated the ratio of cytokines released by Th1/Th2 cells}

The effects of laurotetanine on levels of cytokines of IL-4, IL-6, IL-13, and IFN- $\gamma$ in BALFs are summarized in Figure 5. After the OVA challenge, the cytokines released by Th2 cells in BALFs (IL-4, IL-6, and IL-13) were significantly increased $(p<0.01)$ compared to the normal rats. In contrast, the IFN- $\gamma$ released by Th1 cells was significantly decreased $(p<0.01)$ compared to the normal rats. Interestingly, the three cytokines were significantly $(p<0.01)$ decreased by treatments with laurotetanine $(20,40$, and 60 $\mathrm{mg} / \mathrm{kg}$ ) and Montelukast (30 mg/kg), whereas IFN- $y$ was increased significantly $(p<0.01)$, compared to control rats.
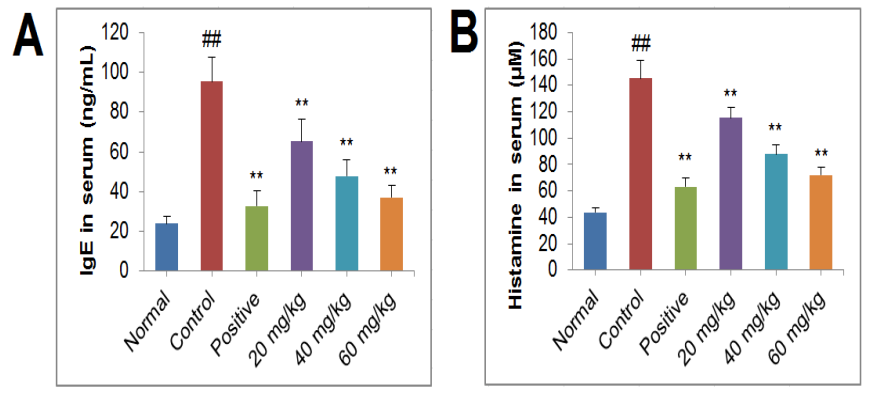

Figure 4: Effect of Laurotetanine on levels of $\lg E$ and histamine in serum. Data are represented as mean \pm SD $(\mathrm{n}=10) ;{ }^{\# \#} p<0.01$ vs. Normal; ${ }^{\star *} p<0.01$, vs. Control
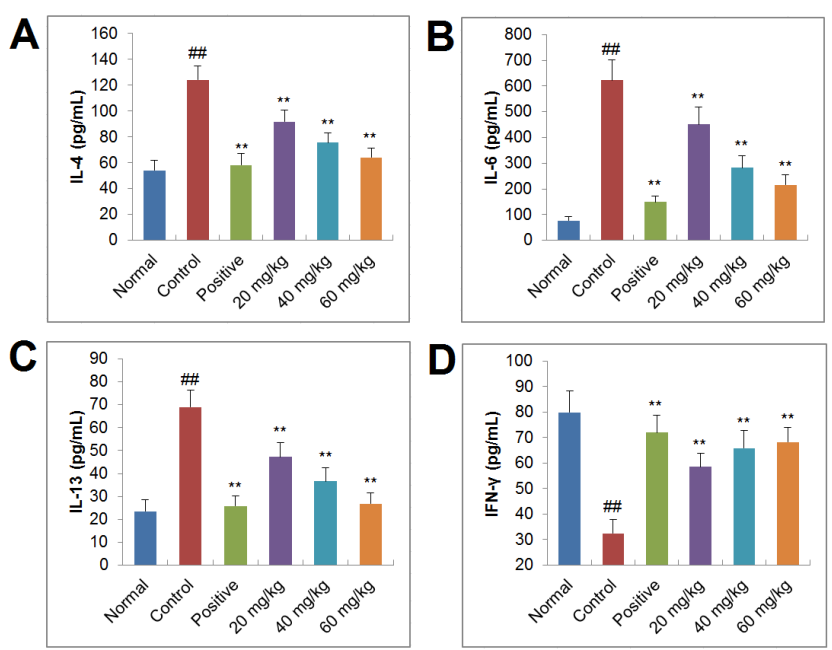

Figure 5: Effect of laurotetanine on levels of cytokines of IL-4, IL-6, IL-13 and IFN- $\gamma$ in BALFs. Data are represented as mean $\pm \mathrm{SD}(\mathrm{n}=10) ;{ }^{\# \#} p<0.01$ vs. Normal; ${ }^{* *} p<0.01$, vs. control

Trop J Pharm Res, June 2019; 18(6): 1280 
Laurotetanine regulated the expressions of MUC5AC, NF-kB p65, and IKB in lung tissues

In order to explore the potential molecular mechanisms of laurotetanine, western blot assays were carried out to determine the protein expressions of MUC5AC, NF-kB p65, and IKB in lung tissues. As shown in Figure 6 , the results indicate that the OVA challenge up-regulated MUC5AC $(p<0.01)$ and down-regulated NF-KB $(p<0.01)$ and IKB $(p<0.01)$ in lung tissues. However, laurotetanine treatment $(40$ and 60 $\mathrm{mg} / \mathrm{kg}$ ) significantly decreased MUC5AC ( $p<$ $0.01)$ and increased NF-KB p65 $(p<0.01)$ and IKB $(p<0.01)$ in lung tissues compared to control asthmatic rats.
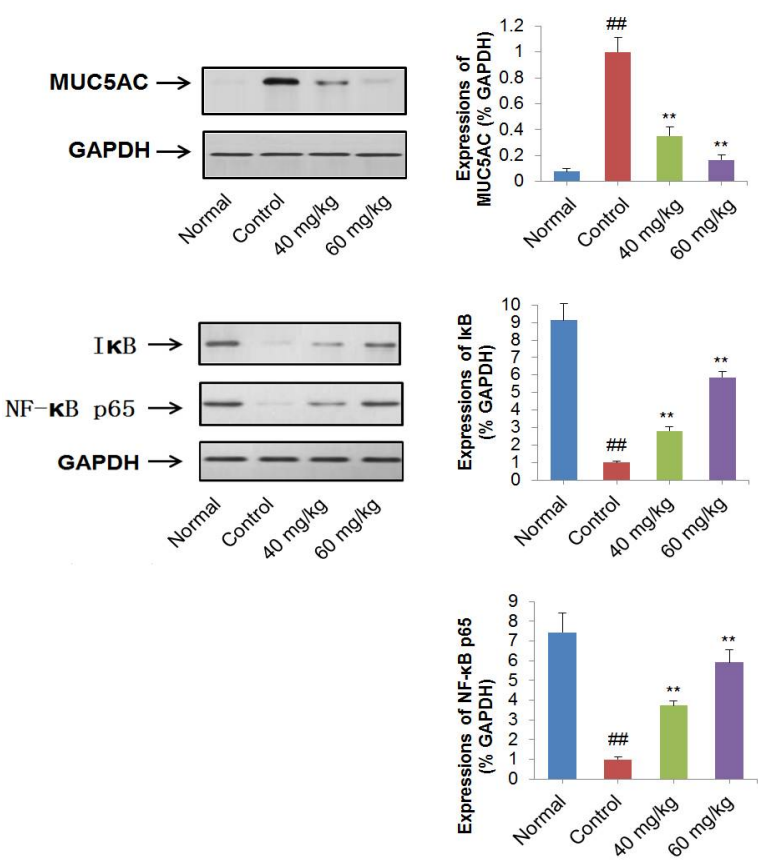

Figure 6: Effect of laurotetanine on protein expressions of MUC5AC, NF-kB p65 and IKB in lung tissues. Data are represented as mean \pm SD $(n=10)$; ${ }^{\# \#} p<0.01$ vs. normal; ${ }^{* *} p<0.01$, vs. control

\section{DISCUSSION}

Natural herbal medicines have been used for preventing or curing diseases for thousands of years [7]. Yet, this study reports the antiasthmatic effects of a monomer (laurotetanine) isolated from the roots of $L$. cubeba on OVAinduced allergic asthma and its potential molecular mechanisms for the first time.

The $\lg \mathrm{E}$ and histamine are considered as two crucial biomarkers for allergical diseases and also as two drug targets for treating allergic asthma $[17,18]$. Based on previous studies, there are abundant natural agents reported to be found from natural plants with remarkable antialleric effects via blocking IgE and histamine [17-19]. In the present study, laurotetanine suppressed $\lg E$ and histamine in the serum of asthmatic rats, indicating that laurotetanine possesses a potential anti-asthma property. Increasingly, studies are showing that over-secretion of MUC5AC in airway epithelial cells is a key feature of allergic asthma, and that downregulating MUC5AC is a good strategy for treating asthma $[17,20]$.

The present results demonstrate that laurotetanine possessed the potential to downregulate the MUC5AC in lung tissues of asthmatic rats. Furthermore, because airway inflammatory reaction is the main symptom of allergic asthma, controlling airway inflammation could be beneficial for alleviating the severity of allergic asthma $[17,21]$. To evaluate the effects of laurotetanine on airway inflammatory reactions in allergic asthma, four inflammatory cells (eosinophils, neutrophils, lymphocytes, and macrophages) in BALF were assessed, and the results show that laurotetanine had a good inhibitory effect against inflammatory cell production. Previous reports reveal that an imbalance of Th1/Th2 is crucial for allergic asthma and that a decrease in the cytokines released by Th2 cells, (e.g., IL-4, IL-6, and IL-13) could be helpful for controlling asthma. Thus, the appropriate ratio of Th1/Th2 is also beneficial for management of allergic diseases $[15,16,18]$.

The present results show that laurotetanine reduced IL-4, IL-6, and IL-13, but increased IFN$\mathrm{Y}$, which is a cytokine released by Th1 cells. This finding reveals that laurotetanine could be beneficial for the balance of Th1/Th2. The NF-KB signal pathway, which is composed of two subunits (i.e., p50 and p65), is crucial for inflammation $[22,23]$ and is generally localized in the cytoplasm by the IKB protein [22,24]. Inflammatory reactions could be triggered as NF$\mathrm{KB}$ translocates to the nucleus by dissociating from IkB. Also, NF-kB could further up-regulate the release of inflammatory enzymes and cytokines (e.g., TNF- $\alpha$, IL-1, IL-4, IL-6, and IL13), thereby aggravating inflammatory reactions [25]. In the present results, laurotetanine upregulated the expressions of IKB and NF-KB p65 in cytoplasm, indicating this compound possesses an inhibitory effect against the nuclear transfer of NF-KB. Overall, these results indicate that the inhibitory effects of laurotetanine on the NF-KB signal pathway may be a potential mechanism for its anti-asthmatic effects.

\section{CONCLUSION}

The present results indicate that laurotetanine exerted an anti-asthmatic effect in rats by 
inhibiting $\lg \mathrm{E}$, histamine, and inflammatory reactions via down-regulation of the MUC5AC and NF-KB signal pathways in lung tissues. Thus, the findings lend support for the further development of laurotetanine as a candidate drug for treating allergic asthma.

\section{DECLARATIONS}

\section{Conflict of interest}

No conflict of interest is associated with this work.

\section{Contribution of authors}

We declare that this work was done by the authors named in this article and all liabilities pertaining to claims relating to the content of this article will be borne by the authors.

\section{Open Access}

This is an Open Access article that uses a funding model which does not charge readers or their institutions for access and distributed under the terms of the Creative Commons Attribution License (http://creativecommons.org/licenses/by/ 4.0) and the Budapest Open Access Initiative (http://www.budapestopenaccessinitiative.org/rea d), which permit unrestricted use, distribution, and reproduction in any medium, provided the original work is properly credited.

\section{REFERENCES}

1. Tung HY, Li E, Landers C, Nguyen A, Kheradmand F, Knight JM, Corry DB. Advances and evolving concepts in allergic asthma. Semin Respir Crit Care Med 2018, 39(1): 64-81.

2. Radermecker $C$, Louis R, Bureau F, Marichal T. Role of neutrophils in allergic asthma. Curr Opin Immunol 2018; 54: 28-34.

3. Woehlk $C$, von Bülow $A$, Kriegbaum $M$, Backer $V$, Porsbjerg C. Allergic asthma is associated with increased risk of infections requiring antibiotics. Ann Allergy Asthma Immunol 2018, 120(2): 169-176.

4. Chinese Thoracic Society. Guidelines for asthma prevention and treatment. Chin J Tuberc Respir Dis 2016, 39(9): 675-697.

5. Dong $F$, Wang $C$, Duan J, Zhang W, Xiang D, Li M. Puerarin attenuates ovalbumin-induced lung inflammation and hemostatic unbalance in rat asthma model. Evid Based Complement Alternat Med 2014, 2014:726740.

6. Zhang XF, Huang JP, Li BY, Peng L. Review of mechanism of traditional Chinese Medicines to treat asthma. Chinese J Exp Trad Med Formul 2013, 19(15): 344-347.

7. Wu WY, Hou JJ, Long HL, Yang WZ, Liang J, Guo DA. TCM-based new drug discovery and development in China. Chin J Nat Med 2014, 12(4):241-250.

8. Wu FW, Fu WH, Cheng BJ. Constituents research on the volatile oil of Litsea cubeba (Lour) Pers. Chin J Chin Mater Medica 1990, 15(4):232.

9. Lin $B$, Sun $L N$, Xin $H L$, Nian $H$, Song $H T$, Jiang $Y P$, Wei $Z Q$, Qin $L P$, Han T. Anti-inflammatory constituents from the root of Litsea cubeba in LPS-induced RAW 264.7 macrophages. Pharm Biol 2016, 54(9): 1741-1747.

10. Yin SW, Zhu F, Liu LP, Chen CX, Gao XY, Dang BT, He $X M$. Screening antifungal component from Litsea cubeba 2011, 23: 734-738.

11. Lee SS, Chen CK, Chen IS, Liu KCS. Additional isoquinoline alkaioids from Litsea cubeba. J Chin Chem Soc 2013, 39 (5): 453-455.

12. Zhang $S Y$, Guo $Q$, Gao $X L$, Guo $Z Q$, Zhao $Y F$, Chai $X Y$, Tu PF. A phytochemical and pharmacological advance on medicinal plant Litsea cubeba (Lauraceae). Chin J Chin Mater Medica 2014, 39(5): 769-776.

13. Zhao QZ, Zhao YM, Wang KJ. Alkaloids from the root of Lindera angustifolia. Acta Pharm Sinica 2005, 40(10): 931-934.

14. Committee on Animal Research and Ethics (CARE). Guidelines for Ethical Conduct in the Care and Use of Nonhuman Animals in Research. http://www.apa.org/science/leadership/care/guidelines.a spx.

15. Liu YZ, Xu WC, Ming X, Zhan XG, Bai L, Xue Z, Yu JE. Effects of tMa-Xin-Di-Tan decoction on ovalbumininduced allergic asthma in mice. Trop $J$ Pharm Res 2018, 17 (5): 803-808.

16. Fu W, Zhao J, Liu X, Gao Y, Zheng $C$. The roles of the $T L R / N F$ TKB signaling pathway in the mutual interactions between the lung and the large intestine. Mol Med Rep 2018, 18(2):1387-1394.

17. Lee MY, Shin IS, Jeon WY, Lim HS, Kim JH, Ha H. Pinellia ternata Breitenbach attenuates ovalbumininduced allergic airway inflammation and mucus secretion in a murine model of asthma. Immunopharmacol Immunotoxicol 2013, 35(3): 410-418.

18. Li Q, Ding W, Gao Y, Li Y, Jiang L, Jiang Y. Imperatorin inhibits allergic airway inflammatory reaction and mucin secretion in ovalbumin-induced asthmatic rats. Trop $J$ Pharm Res 2016, 15(11): 1319-1326.

19. Peng W, Liu YJ, Wu N, Sun T, He XY, Gao YX, Wu CJ. Areca catechu L. (Arecaceae): a review of its traditional uses, botany, phytochemistry, pharmacology and toxicology. J Ethnopharmacol. 2015; 164: 340-56.

20. Shao MX, Ueki IF, Nadel JA. Tumor necrosis factor alpha-converting enzyme mediates MUC5AC mucin expression in cultured human airway epithelial cells. Proc Natl Acad Sci USA 2003, 100(20): 11618-11623.

21. Shin IS, Lee MY, Jeon WY, Shin NR, Seo CS, Ha $H$. EBM84 attenuates airway inflammation and mucus 
hypersecretion in an ovalbumin-induced murine model of asthma. Int $\mathrm{J} \mathrm{Mol} \mathrm{Med} \mathrm{2013,} \mathrm{31(4):} \mathrm{982-988.}$

22. Li Q, Yang S, Yang S, Xin F, Wang M. Anti-inflammatory activity of phlomisoside $F$ isolated from Phlomis younghusbandii Mukerjee. Int Immunopharmacol 2015, 28(1): 724-730.

23. Pikarsky E, Porat RM, Stein I, Abramovitch R, Amit S, Kasem S, Gutkovich-Pyest E, Urieli-Shoval S, Galun E, Ben-Neriah Y. NF-kappaB functions as a tumour promoter in inflammation-associated cancer. Nature 2004, 431(7007):461-466.

24. Scott ML, Fujita T, Liou HC, Nolan GP, Baltimore D. The p65 subunit of NF-kappa $B$ regulates I kappa $B$ by two distinct mechanisms. Genes Dev 1993, 7(7A):12661276.

25. Gu $X$, Zhang $Q, D u Q$, Shen $H$, Zhu Z. Pinocembrin attenuates allergic airway inflammation via inhibition of NF-KB pathway in mice. Int Immunopharmacol 2017, 53:90-95 